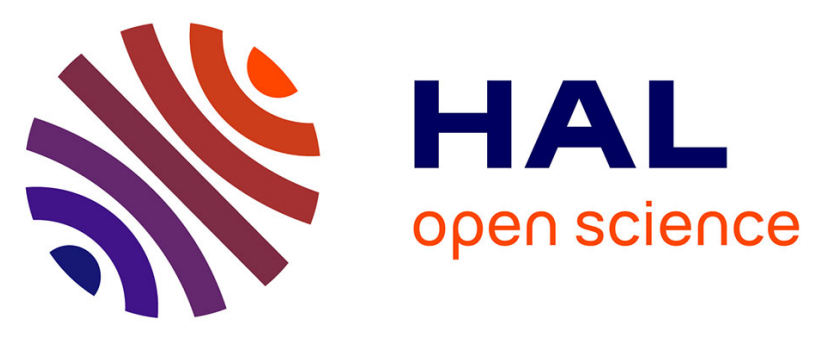

\title{
The novel photoresponsive oligomers containing azo derivatives of sulfamerazine for spontaneous surface relief grating inscription
}

Aleksandra Korbut, Sonia Zielinska, Régis Barille, Jacek Piglowski, Ewelina Ortyl

\section{To cite this version:}

Aleksandra Korbut, Sonia Zielinska, Régis Barille, Jacek Piglowski, Ewelina Ortyl. The novel photoresponsive oligomers containing azo derivatives of sulfamerazine for spontaneous surface relief grating inscription. European Polymer Journal, 2017, 90, pp.392-406. 10.1016/j.eurpolymj.2017.03.024 . hal-02564446

\section{HAL Id: hal-02564446 \\ https://univ-angers.hal.science/hal-02564446}

Submitted on 26 May 2021

HAL is a multi-disciplinary open access archive for the deposit and dissemination of scientific research documents, whether they are published or not. The documents may come from teaching and research institutions in France or abroad, or from public or private research centers.
L'archive ouverte pluridisciplinaire HAL, est destinée au dépôt et à la diffusion de documents scientifiques de niveau recherche, publiés ou non, émanant des établissements d'enseignement et de recherche français ou étrangers, des laboratoires publics ou privés.

\section{(c)(1)}

Distributed under a Creative Commons Attribution| 4.0 International License 


\title{
The novel photoresponsive oligomers containing azo derivatives of sulfamerazine for spontaneous surface relief grating inscription
}

\author{
Aleksandra Korbut $^{1}$, Sonia Zielińska ${ }^{1}$, Regis Barille ${ }^{2}$, Jacek Pigłowski ${ }^{1}$, Ewelina Ortyl ${ }^{1 *}$ \\ ${ }^{1}$ Wrocław University of Technology, Faculty of Chemistry, Department of Polymer \\ Engineering and Technology, 50-370 Wrocław, Poland \\ ${ }^{2}$ Laboratoire Moltech Anjou Université d'Angers/UMR CNRS 6200 2, Bd Lavoisier, 49045 \\ Angers, France \\ e-mail: aleksandra.korbut@pwr.edu.pl,sonia.zielinska@pwr.edu.pl,regis.barille@univ- \\ angers.fr, jacek.piglowski@pwr.edu.pl, ewelina.ortyl@pwr.edu.pl \\ *Corresponding author: Ewelina Ortyl, ewelina.ortyl@pwr.edu.pl
}

\begin{abstract}
In this work, a novel photoresponsive materials has been successfully developed. We have synthesized the series of azopolymers containing derivatives of sulfamerazine and studied their photochromic properties. The polymers were obtained from methacrylate azomonomers, butyl methacrylate and isobornyl methacrylate by radical polymerization. Spectral properties and photoisomerization kinetic constants were determined for thin transparent films, using UV-Vis spectroscopy. The maximum absorption of the films was observed at $432-440 \mathrm{~nm}$. The obtained materials showed ability to reversible trans-cis photoisomerization. Reversibility of the process was confirmed during ellipsometric measurements. The change of the real part of the complex refractive index induced by laser irradiation was between 0.010 and 0.053 . Additionally, some properties of described polymers and azobenzene derivatives were calculated and were utilized in order to better understand the differences in the photochromic behaviour of the new materials. Moreover, we determined the suitability of the obtained azopolymers for spontaneous surface relief grating inscription. Spontaneous surface relief grating recording on the thin azopolymer films was carried out using set-up with one laser beam. The spontaneous SRG was successfully recorded in all investigated polymers.
\end{abstract}

Keywords: azopolymers; trans-cis photoisomerization; surface relief grating 


\section{Introduction}

In the past decade, fast development of nonlinear optics and optoelectronics is observed. The amount of stored and transformed information has rapidly increased and it causes the necessity to create new materials with higher density of information recording [1-3]. Hence, the photoresponsive materials have increasing interest in materials science and technology [4,5]. Among the photoactive materials, the photochromic polymers have a strong position [6]. In almost all of cases, these polymers contain covalently linked derivatives of azobenzene. The chromophores can be built into the main chain or into the side chain of the polymer. It is also possible to form the guest-host systems, where azo dye is randomly dispersed into a polymer matrix without forming the covalent bond between matrix and azo compound. The photochromic polymers have great interest because of their attractive properties and applications in many fields, such as optical data storage [7], holographic memories [8,9], optical switches [10,11] or surface relief gratings [12,13]. Aromatic azo compounds are widely used as dyes, pigments and $\mathrm{pH}$ indicators [14,15]. Most of the interesting properties of azopolymers are directly related with the trans-cis photoisomerization of the azobenzene units in the polymeric structures [16]. Under light irradiation trans isomer undergo a transformation into less stable cis isomer. During the thermal relaxation, decline of the cis-form and return to the trans-form is observed. The thermal relaxation occurs in the dark or under light illumination with the appropriate wavelength. Reversible trans-cis photoisomerization induces a number of changes the physicochemical properties of the material [17].

The photochromic groups incorporated in the side chain of polymer create new opportunities for technological applications in optoelectronics as optical information storage devices. Because of the remarkable photochromic properties azopolymers have been the subject of many studies concerning the potential application in data storage and other optical technologies $[18,19]$. In these kind of polymers, surface relief gratings inscription can be observed at the micrometer scale [20,21]. In the literature, many techniques for the formation of this photoinduced phenomena were described [1, 22-28]. Briefly, SRG can be inscribed on the azopolymer surface by interfering two coherent laser beams of appropriate polarization [3] or by one single beam method [23,25]. Surface grating inscription has been studied since 1990' and published by Tripathy's [29] and Natansohn's group [30].

The possibility and efficiency of SRG inscription depends on structure of azopolymers and their physicochemical properties. Parameters like type of azobenzene compound and its 
content, average molecular weight and glass transition temperature have a strong influence on this process. As a general tendency, SRGs are inscribed at room temperature on azobenzenecontaining polymers with glass transition temperature in the range of $100-190{ }^{\circ} \mathrm{C}$ [31]. In SRG formation process, the average molecular weight of polymers is also important. Generally, the higher molecular weight of polymer causes the lower modulation depth. Due to the increase of viscosity of the polymers with the increasing average molecular weight, the SRG recording is less difficult in the low-molecular weight polymers [32-34]. Moreover, properties of thin films like thickness and homogeneity play an important role in SRG inscription process. A general trend is noticeable: recording SRG in thinner films is possible at shorter exposure and lower intensity of the laser. Furthermore, the depth of inscribed SRG depends on film thickness [22]. It has also been seen that amplitude of modulation increases linearly with time at the beginning of the illumination and reaches saturation at certain depth which depends on the film thickness [33]. The SRG inscription process is related to mass transport phenomenon, thus depends on the mobility of the polymer chains and free volume of the polymer [34,35]. Therefore, polymer physicochemical properties, i.e. viscosity, glass transition temperature and molecular weight plays the key role in SRG formation.

Current investigation shows that materials containing azo derivatives can exhibit the excellent optical properties and photoresponsive variations. The unique photochromic properties are based on the reversible photoinduced trans-cis isomerization.

Recently, spontaneous surface relief grating formation was described in numerous papers for various materials containing azobenzene derivatives in their structures. For example, Noga et al. observed the willow structure formation on the surface of supramolecular complex of 4hydroxy-4'-dimethylaminoazobenzene and poly(4-vinylpyridine) using a single coherent laser beam of linear polarization [36]. In the same year, Mazaheri et al. investigated nucleation and growth of spontaneous surface relief gratings on a Disperse Red 1 (DR1) glass-forming derivative [37]. In another publication, Mazaheri et al. evaluated an influence of temperature on the relaxation kinetics of spontaneous pattern formation in highly photoactive azobenzene copolymer containing heterocyclic sulfonamide moieties [38].

Azobenzene chromophores and polymers containing heterocyclic sulfonamide moieties like sulfamethoxazole, sulfisomidine, sulfamerazine or isoxazole were designed and synthesized in our group [39-44]. These materials have very good optical properties and seem to be promising candidates for novel attractive applications.

Numerous studies were dedicated to various systems of azobenzene derivatives because of their potential applications in many fields. The chromophores were used to obtain a siloxane- 
based hybrid organic-inorganic materials [44,45] polyurethane and methacrylic polymers $[17,42]$ the guest-host structures [44,45] or Langmuir-Blodgett films [43]. Moreover, studies of the photochromism, refractive index modulation [40,42], second harmonic generation [46] or nanoobjects formation [47] were carried out. The promising results encourage us to continue the investigation in that field.

In this work, we present the synthesis and characterization of series of novel photoresponsive methacrylic homopolymers and copolymers. Subsequently, these polymers were used for the spontaneous surface relief grating inscription. The polymers were obtained by radical polymerization in presence of AIBN. The azobenzene chromophore were incorporated as a side chain. We investigated the photochromic properties using UV-Vis spectroscopy and ellipsometry and determined relationship between structure of the macromolecular materials and ability to reversible trans-cis photoisomerization. The influence of the type of azo-derivatives and non-chromophoric compounds on the photochromic properties was studied. Furthermore, kinetics of trans-cis photoisomerization and the thermal relaxation was estimated. This research was also focused on spontaneous SRG formation on azopolymers functionalized with azobenzene derivatives of sulfamerazine. In our study, the one laser beam was used to inscribe spontaneous SRG on the surface of the obtained azopolymer thin films. The surface modulation of polymer thin films was characterized by atomic force microscopy. Moreover, the diffraction efficiency, periodicity and modulation depth were determined.

\section{Experimental section}

\subsection{Materials}

Sulfamerazine, 2-(methylphenylamino)ethanol, 2-(N-ethylanilino)ethanol, azobisisobutyronitrile (AIBN, 98\%), $\gamma$-butyrolactone, $\mathrm{CDCl}_{3}, \mathrm{DMSO}-\mathrm{d}_{6}$, methacrylic anhydride, 4-(dimethylamino)pyridine, 4-methoxyphenol were purchased from Aldrich and were used without further purification. Butyl methacrylate and isobornyl methacrylate were purchased from Aldrich and were purified from the inhibitor by washing with a $10 \%$ sodium hydroxide aqueous solution and then with deionized water until neutralization. After purification the monomers were dried over anhydrous $\mathrm{MgSO}_{4}$. Tetrahydrofuran, pyridine, DMSO, chloroform, sodium nitrite, anhydrous sodium acetate, concentrated hydrochloric acid, glacial acetic acid were purchased from POCH (Poland). 
The azo dyes were synthesized by coupling of the diazonium salt of sulfamerazine with 2(methylphenylamino)ethanol (SMERm) or 2-(N-ethylanilino)ethanol (SMERe). The products were obtained with yields in range of $88-93 \%$. The preparation procedure and characterization details of SMERm and SMERe were described in our previous paper [44]. In our recent work, dye containing derivatives of sulfamerazine was used to form hybrid systems. We observed a high photoactivity of these systems. Moreover, using the obtained sols we succeeded to produce photochromic nanofibers utilizing electrospinning technique. Hence, we used these dyes to obtain the photosensitive monomers and after this the photochromic polymers.

2.3 Synthesis of methacrylic monomers

2.3.1 Synthesis of 2-[N-methyl-4-[(E)-[4-[(4-methylpyrimidin-2-yl)sulfamoyl]phenyl] azo]anilino] ethyl 2-methylprop-2-enoate (M-SMERm)

In a $50 \quad \mathrm{ml} \quad$ flask, $4.3 \mathrm{~g} \quad(0.01 \quad \mathrm{~mol}) \quad$ of $\quad 4-[(\mathrm{E})-[4-[\mathrm{N}-\mathrm{methyl}-(2-$ hydroxyethyl)amino]phenyl]azo]-N-(4-methylpyrimidin-2-yl)benzenesulfonamide (SMERm), 4-(dimethylamino)pyridine (0.12 $\mathrm{g})$ and 4-methoxyphenol $(0.006 \mathrm{~g})$ were dissolved in $20 \mathrm{ml}$ of anhydrous pyridine. Then, methacrylic anhydride $(0.013 \mathrm{~mol}, 2.0 \mathrm{~g})$, was gradually added dropwise. The reaction mixture was purged with nitrogen and heated under reflux for $15 \mathrm{~min}$. Afterward, the resultant mixture was cooled and poured into an excess amount of water. The precipitated product was filtered under vacuum, washed several times with water and dried at $40{ }^{\circ} \mathrm{C}$. The yield of monomer M-SMERm was $95 \%$.

${ }^{1} \mathrm{HNMR}$ (DMSO-d 6 , TMS, ppm): 1,83, s, 3H $\left(-\left(\mathrm{CH}_{3}\right) \mathrm{C}=\mathrm{C}\right) ; 2,33, \mathrm{~s}, 3 \mathrm{H}\left(\mathrm{CH}_{3}\right.$ in pyrimidine ring at $\mathrm{C} 2$ position); 3,10, s, $3 \mathrm{H}\left(\mathrm{CH}_{3}-\mathrm{N}-\right) ; 3,83$, s, $2 \mathrm{H}\left(-\mathrm{N}-\mathrm{CH}_{2}-\right) ; 4,32$, t, $2 \mathrm{H}\left(-\mathrm{CH}_{2} \mathrm{O}-\right) ; 5,65$, t, $1 \mathrm{H}(-\mathrm{CH}=\mathrm{C}) ; 5,97, \mathrm{~s}, 1 \mathrm{H}(-\mathrm{CH}=\mathrm{C}) ; 6,90-6,93, \mathrm{~m}, 3 \mathrm{H}(\mathrm{CH}$ in pyrimidine ring at $\mathrm{C} 5$ position and protons in benzene ring, ortho position to amine group); 7,81, $\mathrm{d}, J=8,9 \mathrm{~Hz}, 2 \mathrm{H}$ (protons in benzene ring, meta position to amine group); 7,89, d, $J=8,6 \mathrm{~Hz}, 2 \mathrm{H}$ (protons in benzene ring, meta position to $\mathrm{N}=\mathrm{N}$ group); $8,12, \mathrm{~d}, J=8,5 \mathrm{~Hz}, 2 \mathrm{H}$ (protons in benzene ring, ortho position to $\mathrm{N}=\mathrm{N}$ group); $8,33, \mathrm{~d}, J=5,1 \mathrm{~Hz}, 1 \mathrm{H}(\mathrm{CH}$ in pyrimidine ring at $\mathrm{C} 6$ position); $12,0, \mathrm{~s}, 1 \mathrm{H}$ ($\mathrm{NH}-\mathrm{SO}_{2}$ ).

2.3.1.1 Synthesis of 2-[N-ethyl-4-[(E)-[4-[(4-methylpyrimidin-2-yl)sulfamoyl]phenyl]azo] anilino]ethyl 2-methylprop-2-enoate (M-SMERe) 
According to the procedure described in the synthesis of M-SMERm, monomer M-SMERe was obtained. $4.4 \mathrm{~g}(0.01 \mathrm{~mol})$ of 4-[(E)-[4-[N-ethyl-(2-hydroxyethyl)amino]phenyl]azo]-N(4-methylpyrimidin-2-yl)benzenesulfonamide (SMERe) was used instead of SMERm. The yield of M-SMERe was $96 \%$.

${ }^{1} \mathrm{HNMR}$ (DMSO-d $\mathrm{d}_{6}$, TMS, ppm): 1,86, s, 3H $\left(\left(-\mathrm{CH}_{3}\right) \mathrm{C}=\mathrm{C}\right) ; 2,33, \mathrm{~s}, 3 \mathrm{H},\left(\mathrm{CH}_{3}\right.$ in pyrimidine ring at $\mathrm{C} 2$ position); 3,35, s, $2 \mathrm{H},\left(\mathrm{CH}_{3} \underline{\mathrm{CH}}_{2} \mathrm{~N}-\right) ; 3,52-3,56\left(\mathrm{~m}, 2 \mathrm{H}, \underline{\mathrm{CH}}_{3} \mathrm{CH}_{2} \mathrm{~N}-\right)$; 3,77, t, $2 \mathrm{H}(-$ $\left.\mathrm{N}-\mathrm{CH}_{2-}\right) ; 4,32$, t, 2H, (-CH $\left.\mathrm{CH}_{2} \mathrm{O}\right) ; 5,68, \mathrm{~s}, 1 \mathrm{H}(-\mathrm{CH}=\mathrm{C}) ; 6,02, \mathrm{~s}, 1 \mathrm{H}(-\mathrm{CH}=\mathrm{C}) ; 6,89-6,93, \mathrm{~m}, 3 \mathrm{H}$ $(\mathrm{CH}$ in pyrimidine ring at $\mathrm{C} 5$ position and protons in benzene ring, ortho position to amine group); 7,79, t, $J=3,4 \mathrm{~Hz}, 2 \mathrm{H}$ (protons in benzene ring, meta position to amine group); 7,89, $\mathrm{d}, J=8,4 \mathrm{~Hz}, 2 \mathrm{H}$ (protons in benzene ring, meta position to $\mathrm{N}=\mathrm{N}$ group); 8,33, d, $J=5,2 \mathrm{~Hz}$, $2 \mathrm{H}$ (protons in benzene ring, ortho position to $\mathrm{N}=\mathrm{N}$ group); 8,58, d, J=4,2 Hz, $1 \mathrm{H}(\mathrm{CH}$ in pyrimidine ring at $\mathrm{C} 6$ position); 12,10, s, $1 \mathrm{H}\left(-\mathrm{NH}-\mathrm{SO}_{2}\right)$.

\subsection{Synthesis of homopolymers and copolymers}

The methacrylate homopolymers and copolymers were obtained by radical polymerization in presence of AIBN. In a $50 \mathrm{ml}$ flask, the initiator (10\% by weight towards monomers) and $1.0 \mathrm{~g}$ of monomer [and co-monomer in proportions $1 / 1$ ( $\mathrm{mol} / \mathrm{mol})$ for copolymers] were placed and the air was removed with nitrogen stream. Then, $15 \mathrm{ml}$ of the mixture of solvents: $\mathrm{THF} / \gamma$-butyrolactone $=7 / 3(\mathrm{v} / \mathrm{v})$ was added. The reaction mixture was heated under reflux and nitrogen atmosphere for $72 \mathrm{~h}$. After this time, the mixture was cooled and poured into an excess amount of water. The precipitate was collected by filtration under vacuum, washed with water and dried at $50{ }^{\circ} \mathrm{C}$. The yield of resultant polymers was $85-96 \%$. The structures of the obtained polymers were confirmed by ${ }^{1} \mathrm{H}$ NMR. 


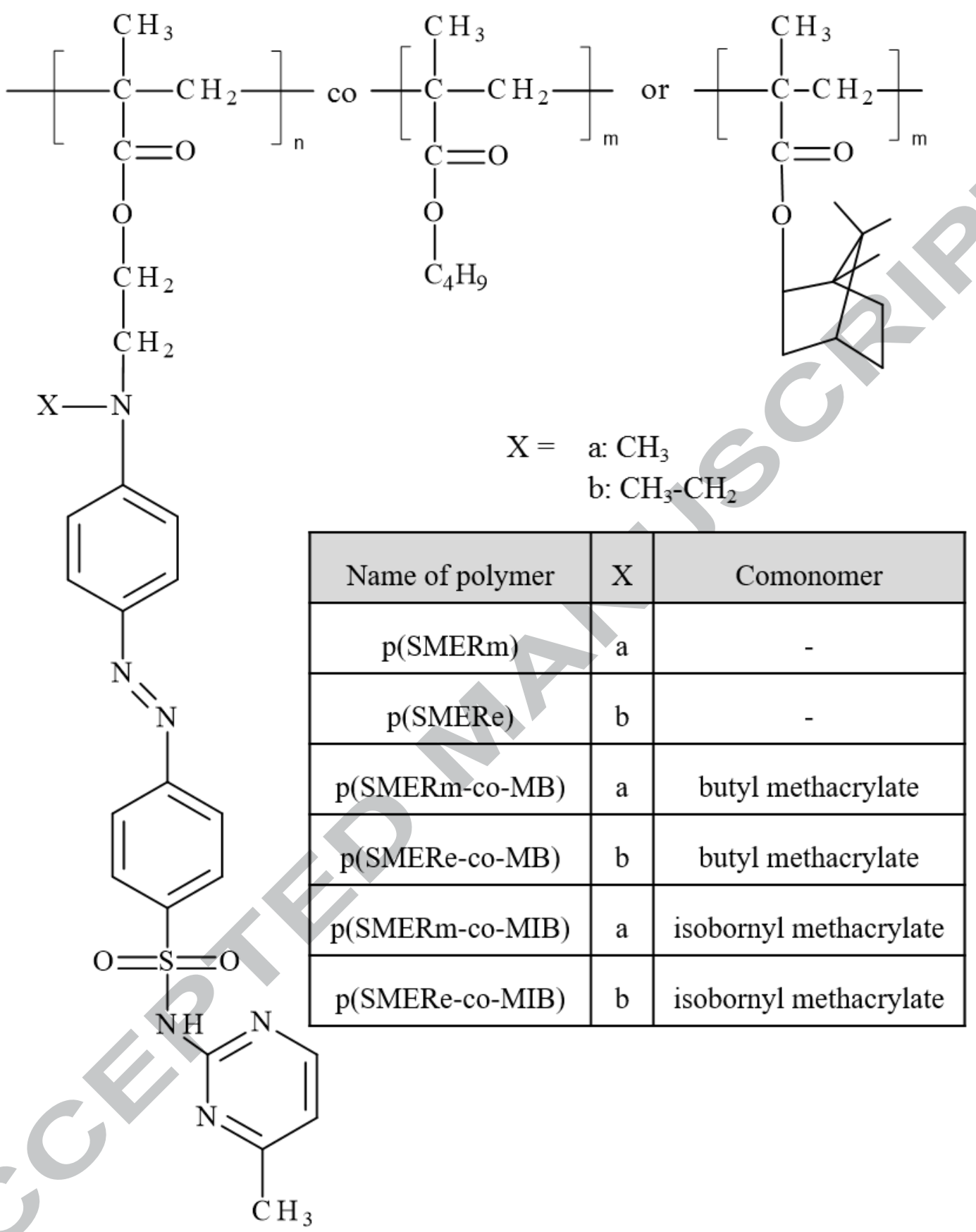

Figure 1. Chemical structure of the synthesized azopolymers.

2.4.1 ${ }^{1}$ HNMR analysis of poly(2-[N-methyl-4-[(E)-[4-[(4-methylpyrimidin-2yl)sulfamoyl]phenyl]azo]anilino]ethyl 2-methylprop-2-enoate), [p(SMERm)]

${ }^{1} \mathrm{HNMR}$ (DMSO-d 6 , TMS, ppm): 1,45 $\left(\left(-\mathrm{CH}_{3}\right) \mathrm{C}-\mathrm{C}\right) ; \sim 1,70-2,00$ (protons in the main chain of polymer); 2,30 $\left(\mathrm{CH}_{3}\right.$ in pyrimidine ring at $\mathrm{C} 2$ position); 3,10 $\left(\mathrm{CH}_{3} \mathrm{~N}-\right) ; \sim 3,60\left(-\mathrm{CH}_{2} \mathrm{~N}-\right)$; $\sim 4,30 \quad\left(-\mathrm{CH}_{2} \mathrm{O}-\right)$; $\sim 6,89$ ( $\mathrm{CH}$ in pyrimidine ring at $\mathrm{C} 5$ position); $\sim 7,60-8,00$ (protons in benzene ring, ortho and meta position to amine group); 8,10-8,40 (protons in benzene ring, 
ortho and meta position to $\mathrm{N}=\mathrm{N}$ group), $\sim 8,52$ ( $\mathrm{CH}$ in pyrimidine ring at $\mathrm{C} 6$ position); $~ 11,9$ $\left(-\mathrm{NH}-\mathrm{SO}_{2}\right)$.

2.4.2 ${ }^{1}$ HNMR analysis of poly(2-[N-ethyl-4-[(E)-[4-[(4-methylpyrimidin-2yl)sulfamoyl]phenyl]azo]anilino]ethyl 2-methylprop-2-enoate), [p(SMERe)]

${ }^{1} \mathrm{HNMR}$ (DMSO, TMS, ppm): 1,13 ((- $\left.\mathrm{CH}_{3}\right) \mathrm{C}-\mathrm{C}$ ); 1,90-2,00 (protons in the main chain of polymer); 2,30 $\left(\mathrm{CH}_{3}\right.$ in pyrimidine ring at $\mathrm{C} 2$ position); $3,35,\left(\mathrm{CH}_{3} \underline{\mathrm{CH}}_{2} \mathrm{~N}-\right) ; \sim 3,52-3,56$, $\left.\mathrm{CH}_{3} \mathrm{CH}_{2} \mathrm{~N}-\right) ; \sim 4,20\left(-\mathrm{CH}_{2} \mathrm{~N}-\right) ; \sim 4,30 \mathrm{ppm},\left(-\mathrm{CH}_{2} \mathrm{O}-\right) ; \sim 6,91(\mathrm{CH}$ in pyrimidine ring at $\mathrm{C} 5$ position); 7,60-7,90 (protons in benzene ring, ortho and meta position to amine group); $8,00-8,20$ (protons in benzene ring, ortho position to $\mathrm{N}=\mathrm{N}$ group); $\sim 8,30$ (protons in benzene ring, meta position to $\mathrm{N}=\mathrm{N}$ group); $~ 8,59$ ( $\mathrm{CH}$ in pyrimidine ring at $\mathrm{C} 6$ position ); 12,0 ($\left.\mathrm{NH}-\mathrm{SO}_{2}\right)$.

2.4.3 ${ }^{1}$ HNMR analysis of poly(2-[N-methyl-4-[(E)-[4-[(4-methylpyrimidin-2yl)sulfamoyl]phenyl]azo]anilino]ethyl 2-methylprop-2-enoate-co-butyl methacrylate), [p(SMERm-co-MB)]

${ }^{1} \mathrm{HNMR}\left(\mathrm{CDCl}_{3}\right.$, TMS, ppm): 0,97-1,40 (protons in butyl methylacrylate mer); $\sim 1,44$ (methylene protons of chromophore mer); 1,94 (methylene protons of nonchromophore mer); $\sim 2,07$ (protons in the main chain of polymer); $\sim 2,45\left(\mathrm{CH}_{3}\right.$ in pyrimidine ring at $\mathrm{C} 2$ position); $\sim 3,15\left(\mathrm{CH}_{3} \mathrm{~N}-\right)$; $\sim 4,17$, (protons in butyl methylacrylate mer); 4,32 (-N- $\left.\mathrm{CH}_{2}-\right)$; $\sim 4,40$ (- $\left.\mathrm{CH}_{2} \mathrm{O}-\right)$; $\sim 6,84$ ( $\mathrm{CH}$ in pyrimidine ring at $\mathrm{C} 5$ position); $\sim 7,89-7,93$ (protons in benzene ring, ortho and meta position to amine group); 8,25 (protons in benzene ring, ortho position to $\mathrm{N}=\mathrm{N}$ group); $~ 8,49$ (protons in benzene ring, meta position to $\mathrm{N}=\mathrm{N}$ group); $\sim 8,50$ ( $\mathrm{CH}$ in pyrimidine ring at $\mathrm{C} 6$ position); 11,90 (-NH-SO 2$)$.

2.4.4 ${ }^{1} \mathrm{HNMR}$ analysis of poly(2-[N-ethyl-4-[(E)-[4-[(4-methylpyrimidin-2yl)sulfamoyl]phenyl]azo]anilino]ethyl 2-methylprop-2-enoate-co-butyl methacrylate), [p(SMERe-co-MB)]

${ }^{1}$ HNMR (DMSO, TMS, ppm): 0,89-1,36 (protons in butyl methylacrylate mer); 1,42 (methylene protons of chromophore mer); 1,85 (methylene protons of nonchromophore mer); 1,90-2,01 (protons in the main chain of polymer); $\sim 2,33\left(\mathrm{CH}_{3}\right.$ in pyrimidine ring at C2 position); $\sim 3,53\left(\mathrm{CH}_{3} \underline{\mathrm{CH}}_{2} \mathrm{~N}\right) ; \sim 3,72\left(\underline{\mathrm{CH}}_{3} \mathrm{CH}_{2} \mathrm{~N}-\right) ; \sim 4,05$ (protons in butyl methylacrylate mer); $\sim 4,22\left(-\mathrm{N}-\mathrm{CH}_{2}-\right) ; 4,35\left(-\mathrm{CH}_{2} \mathrm{O}-\right) ; \sim 6,89(\mathrm{CH}$ in pyrimidine ring at $\mathrm{C} 5$ position); $\sim 7,79-7,89$ (protons in benzene ring, ortho and meta position to amine group); $\sim 8,10-8,12$ 
(protons in benzene ring, ortho position to $\mathrm{N}=\mathrm{N}$ group); $~ 8,30$ (protons in benzene ring, meta position to $\mathrm{N}=\mathrm{N}$ group); 8,62 ( $\mathrm{CH}$ in pyrimidine ring at $\mathrm{C} 6$ position); 11,90 (-NH-SO 2$)$.

2.4.5 ${ }^{1}$ HNMR analysis of poly(2-[N-methyl-4-[(E)-[4-[(4-methylpyrimidin-2yl)sulfamoyl]phenyl]azo]anilino]ethyl 2-methylprop-2-enoate-co-isobornyl methacrylate), [p(SMERm-co-MIB)]

${ }^{1}$ HNMR (DMSO, TMS, ppm): 0,81-1,40 (protons in isobornyl methylacrylate mer); 1,45 (methylene protons of chromophore mer); 1,77 (methylene protons of nonchromophore mer); $\sim 2,34$ (protons in the main chain of polymer); $\sim 2,53\left(\mathrm{CH}_{3}\right.$ in pyrimidine ring at $\mathrm{C} 2$ position); 3,09 $\left(\mathrm{CH}_{3} \mathrm{~N}-\right)$; 3,61 (-N-CH $\left.2_{2}\right) ; ~ 4,27\left(-\mathrm{CH}_{2} \mathrm{O}-\right)$; 6,83 $(\mathrm{CH}$ in pyrimidine ring at C5 position); 7,81-7,90 (protons in benzene ring, ortho and meta position to amine group); $\sim 8,11$ (protons in benzene ring, ortho position to $\mathrm{N}=\mathrm{N}$ group); $\sim 8,32$ (protons in benzene ring, meta position to $\mathrm{N}=\mathrm{N}$ group); $\sim 8,50$ ( $\mathrm{CH}$ in pyrimidine ring at $\mathrm{C} 6$ position); $~ 11,80$ (-NH$\left.\mathrm{SO}_{2}\right)$.

2.4.6 ${ }^{1}$ HNMR analysis of poly(2-[N-ethyl-4-[(E)-[4-[(4-methylpyrimidin-2yl)sulfamoyl]phenyl]azo]anilino]ethyl 2-methylprop-2-enoate-co-isobornyl methacrylate), [p(SMERe-co-MIB)]

${ }^{1} \mathrm{HNMR}\left(\mathrm{CDCl}_{3}\right.$, TMS, ppm): 0,88-1,39 (protons in isobornyl methylacrylate mer); $\sim 1,57$ (methylene protons of chromophore mer); 1,96 (methylene protons of nonchromophore mer); $\sim 2,11$ (protons in the main chain of polymer); $\sim 2,45\left(\mathrm{CH}_{3}\right.$ in pyrimidine ring at $\mathrm{C} 2$ position); 3,54 $\left(\mathrm{CH}_{3} \underline{\mathrm{CH}}_{2} \mathrm{~N}-\right) ; \sim 3,69\left(\underline{\mathrm{CH}}_{3} \mathrm{CH}_{2} \mathrm{~N}-\right) ; \sim 4,31\left(-\mathrm{N}-\mathrm{CH}_{2}-\right) ; \sim 4,39\left(-\mathrm{CH}_{2} \mathrm{O}-\right) ; \sim 6,84$ (CH in pyrimidine ring at $\mathrm{C} 5$ position); $~ 7,89-7,92$ (protons in benzene ring, ortho and meta position to amine group); $~ 8,25$ (protons in benzene ring, ortho position to $\mathrm{N}=\mathrm{N}$ group); $\sim 8,48$ (protons in benzene ring, meta position to $\mathrm{N}=\mathrm{N}$ group); $\sim 8,60(\mathrm{CH}$ in pyrimidine ring at C6 position); 11,90 (-NH-SO 2 ).

2.5 Azopolymer thin films preparation

Thin films were prepared from the azopolymer solution by spin-coating technique. The synthesized polymers were dissolved in THF (40 mg/1.2 ml), ultrasonicated for $30 \mathrm{~min}$. and filtered through syringe filter. For spin-coating Laurell'sWS-400-B - 6NPP-LITE spin coater was used and the spin-up speed was set at $1200 \mathrm{rpm}$ for $40 \mathrm{~s}$. After deposition the films were dried at $50{ }^{\circ} \mathrm{C}$ for $24 \mathrm{~h}$. 


\subsection{Characterization methods}

\subsubsection{Computer simulations}

For quantum chemical calculations Gaussian 09 software was used [48]. Geometry of repeating units occurring in polymers described in this work was optimized using RHF method and 3-21g basis set. The same method and basis set was used to calculate the first hyperpolarizability of azobenzene-containing molecules, characterizing their nonlinear optical properties. That combination gave very reasonable results in our previous works $[41,49]$. Materials Studio package was used to calculate selected properties of polymers using Synthia module. The calculations were performed in order to explain better the differences observed between new materials in question.

\subsection{2 ${ }^{1}$ H NMR spectroscopy}

${ }^{1} \mathrm{H}$ NMR spectra were recorded with a NMR Bruker AvanceTM600 MHz spectrometer using $\mathrm{CDCl}_{3}$ and DMSO- $\mathrm{d}_{6}$ as solvent and tetramethylsilane as an internal standard.

\subsubsection{Differential scanning calorimetry}

Glass transition temperatures of the polymers were determined with a Mettler Toledo 821e DSC apparatus. The heating and cooling rate were $10 \mathrm{~K} / \mathrm{min}$.

\subsubsection{Average molecular weights}

Average molecular weights of the polymers were determined by GPC. The measurements were carried out using azopolymer solutions in DMF with the addition of $5 \mathrm{mmol} / \mathrm{L} \mathrm{LiBr}$. Polystyrene standards were used as reference.

\subsubsection{UV-Vis spectroscopy}

UV-Vis spectra were recorded on HITACHI U-1900 Spectrophotometer. The measurements were carried out for the thin films prepared by spin-coating technique. Before measurements, the samples were stored in the dark at room temperature overnight to ensure that all of the azobenzene units were in the trans configuration. The polymer thin films were irradiated with laser beam with $445 \mathrm{~nm}$ wavelength.

All measurements were performed at room temperature. 


\subsubsection{Ellipsometry}

Ellipsometric measurements were performed with EL X-02C Ellipsometer, DRE-Dr, Ellipsometerbau Gmbh (Germany) operating at an incident angle of $70{ }^{\circ} \mathrm{C}$ and using linearly polarized laser beam of $632 \mathrm{~nm}$ and ca. $3 \mathrm{~mW}$ power.

All measurements were carried out at room temperature.

\subsubsection{Thickness measurements}

The thickness of the analysed thin polymer films were measured using Dektak 32 Profilometer.

\subsubsection{Laser irradiation}

A linearly polarized $\mathrm{Ar}^{+}$laser beam at $473 \mathrm{~nm}$ and $400 \mathrm{~mW} / \mathrm{cm}^{2}$ power was used as the light source for surface relief grating inscription. All experiments were performed at room temperature under air-ambient conditions.

For trans-cis isomerization studies using UV-Vis and ellipsometry the $445 \mathrm{~nm}$ laser with $50 \mathrm{~mW}$ maximum power was used for illumination.

\subsubsection{Atomic Force Microscopy}

After samples surface illumination with argon laser during one hour, the AFM observations were performed to characterize surface of the polymer thin films. The microscopic measurements were carried out using Nanoobserver from CS Istruments. The measurements were conducted using Contact mode.

3. Results and discussion

\subsection{Synthesis}

The methacrylic monomers (M-SMERm or M-SMERe) were used to obtain the photochromic homopolymers or copolymers by radical polymerization. The chemical structures of the synthesized polymers are shown in Figure 1. Obtained polymers contain two types of azobenzene chromophore: 4-[(E)-[4-[methyl(2-hydroxyethyl)amino]phenyl]azo]-N(4-methylpyrimidin-2-yl)benzenesulfonamide $\quad(\mathrm{SMERm}) \quad$ or $\quad 4-[(\mathrm{E})$-[4-[ethyl(2hydroxyethyl)amino]phenyl]azo]-N-(4-methylpyrimidin-2-yl)benzenesulfonamide (SMERe) moieties. The copolymers contain butyl methacrylate or isobornyl methacrylate as 
nonchromophoric part. All of the methacrylate polymers and copolymers were synthesized with high yields (84-96\%) and purity, therefore were used without any further purification. Structures of the investigated polymers were confirmed by ${ }^{1}$ HNMR spectroscopy. Series of the synthesized polymers showed signal characteristic for methyl groups in pyrimidine ring $(\sim 2.30 \mathrm{ppm})$, methyl and ethyl group at nitrogen atom $(\sim 3.10 \mathrm{ppm}$ and $\sim 3.50 \mathrm{ppm}$, respectively) and protons at benzene ring $(\sim 7.60-8.40 \mathrm{ppm})$. Broad multiplets of methylene protons of nonchromophoric mer were visible at $0.80-1.90 \mathrm{ppm}$.

Both of the synthesized monomers showed the vinyl proton signals characteristic for protons at $\mathrm{C}$ atoms in a double bond $\left(\mathrm{CH}_{2}=\mathrm{CH}\right)$ at $\sim 5.65 \mathrm{ppm}$ and $\sim 6.00 \mathrm{ppm}$. On spectra recorded for the polymers these signals not occurred. It may be further confirmation that monomers were reacted completely.

The average molecular weights of the obtained materials determined by GPC were between 1200 and 9300. They were rather low indicating that they were oligomers. It is consistent with literature data for similar materials [50-53]. During synthesis, the high content of the initator was used (10\% by weight towards monomers). This may be associated with these obtained results. However, reduction of amount of the initiator could significantly influence the polymerization efficiency. The low degree of polymerization in discussed oligomers strongly affects the measured polydispersity values. For copolymer p(SMERm-coMIB) which contained isobornyl methacrylate as co-monomer, the molecular weight was the highest and it was 9300. The glass transition temperatures $T_{g}$ of the obtained polymers were in the range of $70-116^{\circ} \mathrm{C}$. The $\mathrm{T}_{\mathrm{g}}$ of copolymers was lower than that of the homopolymers. These results are consistent with the literature data [54]. The lowest $T_{g}$ was for copolymer which contained butyl methacrylate as nonchromophoric part. All values of $\mathrm{T}_{\mathrm{g}}$ are presented in Table 1. Incorporation of nonchromophoric comonomer enable to modify the physical properties of the obtained materials.

Table 1. Selected properties of the obtained polymers

\begin{tabular}{|c|c|c|c|c|c|c|c|c|}
\hline \multirow[t]{2}{*}{ Polymer } & \multicolumn{2}{|c|}{$\lambda_{\max }$} & \multirow{2}{*}{$\begin{array}{c}\text { Absorbance } \\
\text { change } \\
{[\%]}\end{array}$} & \multirow[t]{2}{*}{$\Delta \mathbf{n}_{\mathbf{r}}$} & \multirow{2}{*}{$\begin{array}{c}\text { Film } \\
\text { thickness } \\
{[\mathrm{nm}]}\end{array}$} & \multirow{2}{*}{$\begin{array}{c}\mathbf{T}_{\mathbf{g}} \\
{\left[{ }^{\circ} \mathbf{C}\right]}\end{array}$} & \multirow{2}{*}{$\begin{array}{c}\mathrm{M}_{\mathrm{w}} \\
{[\mathrm{g} / \mathrm{mol}]}\end{array}$} & \multirow[t]{2}{*}{$\mathbf{M}_{w} / \mathbf{M}_{n}$} \\
\hline & $\mathrm{S}^{\mathrm{a}}$ & $\mathrm{F}^{\mathrm{b}}$ & & & & & & \\
\hline p(SMERm) & 445 & 432 & 25 & 0.010 & 484 & 116 & 1200 & 4.7 \\
\hline $\begin{array}{c}\text { p(SMERm- } \\
\text { co-MB })\end{array}$ & 448 & 436 & 34 & 0.053 & 526 & 70 & 4500 & 2.7 \\
\hline $\begin{array}{c}\text { p(SMERm- } \\
\text { co-MIB })\end{array}$ & 445 & 432 & 21 & 0.028 & 468 & 103 & 9300 & 4.3 \\
\hline
\end{tabular}




\begin{tabular}{|c|c|c|c|c|c|c|c|c|}
\hline $\mathbf{p}$ (SMERe) & 452 & 436 & 23 & 0.013 & 481 & 90 & 1200 & 5.6 \\
\hline $\begin{array}{c}\text { p(SMERe- } \\
\text { co-MB) }\end{array}$ & 452 & 440 & 31 & 0.023 & 526 & 80 & 6400 & 3.9 \\
\hline $\begin{array}{c}\text { p(SMERe- } \\
\text { co-MIB) }\end{array}$ & 451 & 436 & 25 & 0.031 & 498 & 85 & 4600 & 3.1 \\
\hline
\end{tabular}

$S^{a}$ - the azopolymer solution,

$F^{b}$ - the azopolymer thin film,

$\Delta \mathrm{n}_{\mathrm{r}}$ - change of the real part of complex refractive index

\subsection{Computer simulations}

The geometry optimization of repeating units present in polymers described in this work was performed using ab initio method RHF and 3-21g basis set. Basic properties derived from geometry optimization and dipole electric field polarizabilities and hyperpolarizabilities calculation results are presented in Table 2. The optimized structures of azobenzenecontaining repeating units are shown in Figure 2.
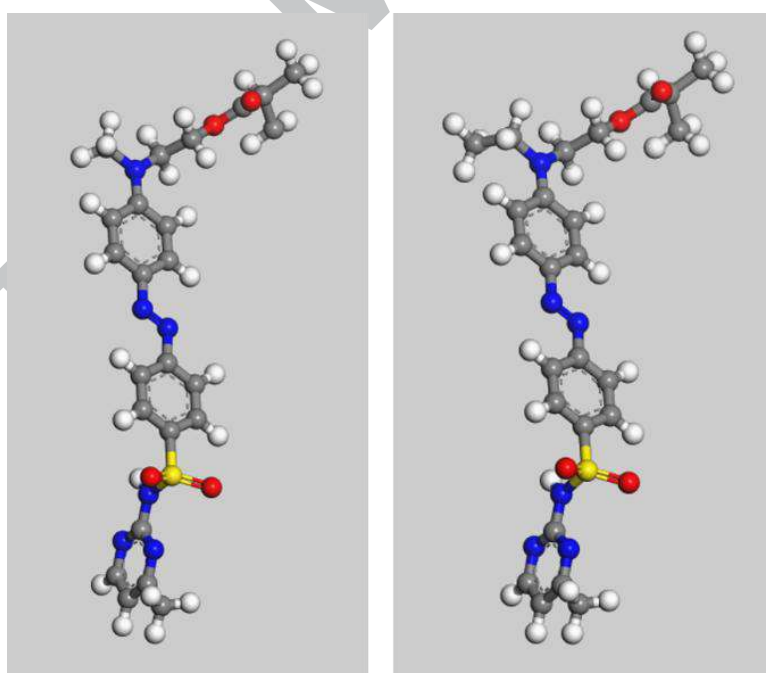

Figure 2. Optimized structures of trans isomers of M-SMERm (left) and M-SMERe (right)

Table 2. Basic properties of trans and cis isomers of sulfamerazine azo derivatives

\begin{tabular}{|l|c|c|c|c|}
\hline & \multicolumn{2}{|c|}{ mSMERm } & \multicolumn{2}{c|}{ mSMERe } \\
\hline & trans & cis & trans & cis \\
\hline$\mu[\mathrm{Cm}] \cdot 10^{30}$ & 29.9 & 6.71 & 30.2 & 6.92 \\
\hline $\begin{array}{l}\text { Molar volume } \\
{\left[\mathrm{cm}^{3} / \mathrm{mol}\right]}\end{array}$ & 379.64 & 326.47 & 381.14 & 296.355 \\
\hline
\end{tabular}




\begin{tabular}{|l|l|l|l|l|}
\hline$\alpha^{0}\left[\mathrm{C}^{2} \mathrm{~m}^{2} \mathrm{~J}^{-1}\right] \cdot 10^{40}$ & 51.5 & 47.2 & 53.4 & 49.1 \\
\hline$\beta^{0}\left[\mathrm{C}^{3} \mathrm{~m}^{3} \mathrm{~J}^{-2}\right] \cdot 10^{50}$ & 17.1 & 6.47 & 18.2 & 7.00 \\
\hline$\Delta \mathrm{HF}[\mathrm{kJ} / \mathrm{mol}]$ & \multicolumn{2}{|c|}{82.12} & \multicolumn{2}{|c|}{82.04} \\
\hline
\end{tabular}

The calculated values of dipole moments, molar volumes, polarizabilities and first hyperpolarizabilities were similar for both compounds due to the very small difference in their chemical structure. The most distinct differences between trans and cis isomers were observable in case of dipole moment and first hyperpolarizability values.

Additional, physicochemical properties calculated using Synthia module for in Materials Studio package, basing on group additive methods, are presented in Table 3. Properties were determined for the temperature $298 \mathrm{~K}$ and the value of molecular weight of homo- and copolymers equal to $10000 \mathrm{amu}$.

Table 3. Properties of homopolymers and copolymers determined using Synthia module in Materials Studio software.

\begin{tabular}{|c|c|c|c|c|c|c|c|}
\hline Polymer & $\mathrm{T}_{\mathrm{g}}\left[{ }^{\circ} \mathrm{C}\right]$ & $\begin{array}{l}\text { Coefficient } \\
\text { of } \\
\text { volumetric } \\
\text { thermal } \\
\text { expansion } \\
{[\mathrm{ppm} / \mathrm{K}]}\end{array}$ & $\begin{array}{l}\text { Density } \\
{[\mathrm{g} / \mathrm{ccm}]}\end{array}$ & $\begin{array}{l}\text { Cp of solid } \\
\text { at } 298 \mathrm{~K} \\
{[\mathrm{~J} /(\mathrm{mol} \cdot \mathrm{K})]}\end{array}$ & $\begin{array}{c}\text { Thermal } \\
\text { conductivity } \\
\text { at } 298 \mathrm{~K} \\
{[\mathrm{~J} /(\mathrm{K} \cdot \mathrm{m} \cdot \mathrm{s})]}\end{array}$ & $\begin{array}{c}\text { Refractive } \\
\text { index at } \\
298 \mathrm{~K}\end{array}$ & $\begin{array}{c}\text { Young's } \\
\text { modulus } \\
{[\mathrm{GPa}]}\end{array}$ \\
\hline $\mathrm{p}(\mathrm{SMERm})$ & 82.8 & 272.5 & 1.28 & 579.3 & 0.159 & 1.587 & 8.25 \\
\hline $\begin{array}{c}\text { p(SMERm-co- } \\
\text { MB) }\end{array}$ & 72.6 & 280 & 1.22 & 397.1 & 0.156 & 1.557 & 5.97 \\
\hline $\begin{array}{c}\text { p(SMERm-co- } \\
\text { MIB })\end{array}$ & 87 & 269.6 & 1.20 & 458.1 & 0.152 & 1.558 & 6.35 \\
\hline$\overline{p(\text { SMERe })}$ & 76.1 & 277.3 & 1.26 & 605 & 0.158 & 1.583 & 8.16 \\
\hline $\begin{array}{c}\text { p(SMERe-co- } \\
\text { MB) }\end{array}$ & 67.7 & 283.6 & 1.21 & 410 & 0.155 & 1.555 & 5.93 \\
\hline $\begin{array}{c}\text { p(SMERe-co- } \\
\text { MIB) }\end{array}$ & 82.4 & 272.8 & 1.19 & 470.9 & 0.151 & 1.556 & 6.32 \\
\hline
\end{tabular}

3.3 Photoisomerization study 
A significant part of this research was focused on investigation of the photoresponsive properties occurring in the obtained materials. For the UV-Vis measurements, the azopolymer thin films and the azopolymer solution in DMSO were prepared.

Before further spectroscopic measurements, the thicknesses of the azopolymer thin films were determined. The thicknesses of the analysed films were comparable and were found to be in the range of $460-530 \mathrm{~nm}$. The summarized results are presented in Table 1.

To ensure that all of the azobenzene units were in the trans configuration, the samples were kept in the dark at room temperature overnight. After this, the reversible trans-cis photoisomerization of the azobenzene moiety in the synthesized polymers was verified. The maximum absorption band of the synthesized polymers was located in the range of 432-440 $\mathrm{nm}$ for the thin films and 445-452 $\mathrm{nm}$ for the azopolymer solutions in DMSO (Table 1). The measurements for the thin azopolymer films were carried out before illumination, after laser irradiation and after the thermal relaxation conducted in the dark. Figure 3 shows the UV-Vis spectra of homopolymer $\mathrm{p}$ (SMERe) thin film after exposure to the laser beam at $445 \mathrm{~nm}$ for different irradiation time. The changes for the other azopolymers are quite similar to these spectra.

Laser irradiation caused the trans-cis photoisomerization of the azo group, resulting in a strong decrease in absorbance at $-440 \mathrm{~nm}$. Hence, the change of the absorbance after irradiation with laser was studied. Based on the resulting spectra, the degree of the trans-cis photoisomerization was estimated (Table 1). The highest change of absorbance was observed for butyl methacrylate copolymers: $\mathrm{p}(\mathrm{SMERm}-\mathrm{co}-\mathrm{MB})$ and $\mathrm{p}(\mathrm{SMERe}-\mathrm{co}-\mathrm{MB})$ and it was $\sim 30 \%$ in the both cases. For homopolymers and copolymers containing isobornyl methacrylate as nonchromophoric comonomer the changes of absorbance were lower $(\sim 20$ 25\%). After about 6-10 minutes irradiation (depends on the sample) no spectral changes were observed and the samples reached a photostationary state. After this time, no further significant changes were observed in spectra. The samples were left in the dark and unstable cis isomer relaxed thermally to the thermodynamically stable trans form. 


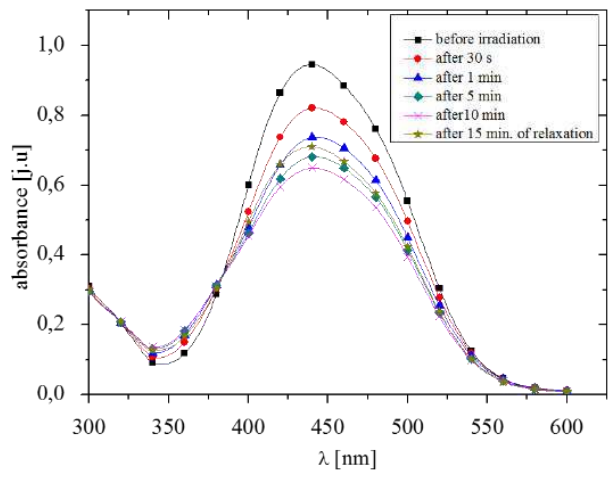

Figure 3. UV-Vis spectral changes of $\mathrm{p}(\mathrm{SMERe})$ thin film during irradiation with $445 \mathrm{~nm}$ for $0.5,1,5,10 \mathrm{~min}$. and after $15 \mathrm{~min}$. of the thermal relaxation.

Moreover, the kinetics of the trans-cis photoisomerization process and the thermal relaxation was studied. According to the exponential equations, the rates of changes in the obtained polymers during the both process were determined. All kinetic parameters are given in Table 4.

Kinetics of the photoinduced trans-cis isomerization process could be described by the second-order kinetics expression [49]. The experimental results can be fitted by the following equation (1):

$$
\left(A_{\infty}-A_{t}\right) /\left(A_{\infty}-A_{0}\right)=\alpha \cdot \exp \left(-k_{1} \cdot t\right)+(1-\alpha) \cdot \exp \left(-k_{2} \cdot t\right)
$$

where $\mathrm{k}_{1}$ is the rate constant of the fast reaction step and $\mathrm{k}_{2}$ is the rate constant of the slow reaction step of the trans-cis photoisomerization, $\alpha$ describes the fraction of fast photoisomerization stage in total conversion of the system, $\mathrm{A}_{0}$ is an initial absorbance (before irradiation), $\mathrm{A}_{\infty}$ is absorbance in the photostationary state and $\mathrm{A}_{t}$ represents absorbance measured at time $\mathrm{t}$.

Table 4. Kinetic data for trans-cis photoisomerization and cis-trans thermal relaxation in the dark determined by UV-Vis measurements for the photochromic polymers thin films.

\begin{tabular}{|c|c|c|c|c|c|c|c|}
\hline \multirow[b]{2}{*}{ Polymer } & \multicolumn{5}{|c|}{ Photoisomerization trans-cis } & \multicolumn{2}{|c|}{$\begin{array}{l}\text { Thermal } \\
\text { relaxation }\end{array}$} \\
\hline & $\mathrm{A}_{\infty} / \mathrm{A}_{0}$ & $\alpha$ & $\begin{array}{c}\mathrm{k}_{1} \cdot 10^{-3} \\
{\left[\mathrm{~s}^{-1}\right]}\end{array}$ & $1-\alpha$ & $\begin{array}{c}\mathrm{k}_{2} \cdot 10^{-3} \\
{\left[\mathrm{~s}^{-1}\right]}\end{array}$ & $\bar{\alpha}$ & $\begin{array}{c}\mathrm{k}_{1} \cdot 10^{-4} \\
{\left[\mathrm{~s}^{-1}\right]}\end{array}$ \\
\hline $\mathrm{p}$ (SMERm) & 0.75 & 0.73 & 19.0 & 0.27 & 223.2 & 0.78 & 1.7 \\
\hline
\end{tabular}




\begin{tabular}{|c|c|c|c|c|c|c|c|}
\hline & & & $( \pm 1.1)$ & & $( \pm 154.4)$ & & $( \pm 0.7)$ \\
\hline p(SMERm-co-MB) & 0.66 & 0.61 & $\begin{array}{c}57.2 \\
( \pm 8.5)\end{array}$ & 0.39 & $\begin{array}{c}11.6 \\
( \pm 2.4)\end{array}$ & 0.82 & $\begin{array}{c}1.9 \\
( \pm 0.6)\end{array}$ \\
\hline p(SMERm-co-MIB) & 0.79 & 0.49 & $\begin{array}{c}3.8 \\
( \pm 1.1)\end{array}$ & 0.51 & $\begin{array}{c}4.8 \\
( \pm 1.4)\end{array}$ & 0.84 & $\begin{array}{c}1.6 \\
( \pm 0.6)\end{array}$ \\
\hline $\mathrm{p}(\mathrm{SMERe})$ & 0.77 & 0.45 & $\begin{array}{c}13.1 \\
( \pm 2.0)\end{array}$ & 0.55 & $\begin{array}{c}60.1 \\
( \pm 9.0)\end{array}$ & .75 & \\
\hline p(SMERe-co-MB) & 0.69 & 0.64 & $\begin{array}{c}45.8 \\
( \pm 5.2)\end{array}$ & 0.36 & $\begin{array}{c}12.0 \\
( \pm 2.1)\end{array}$ & 0.78 & $\begin{array}{c}2.0 \\
( \pm 0.8)\end{array}$ \\
\hline p(SMERe-co-MIB) & 0.75 & 0.53 & $\begin{array}{c}9.9 \\
( \pm 4.0)\end{array}$ & 0.47 & $\begin{array}{r}34.4 \\
( \pm 15.7)\end{array}$ & 0.79 & $\begin{array}{c}2.6 \\
( \pm 0.4)\end{array}$ \\
\hline
\end{tabular}

For the homopolymers $\mathrm{p}(\mathrm{SMERm})$ and $\mathrm{p}(\mathrm{SMERe})$ rate constants of the fast reaction step $\left(\mathrm{k}_{1}\right)$ of the trans-cis isomerization were found to be $19.0 \cdot 10^{-3} \mathrm{~s}^{-1}$ and $13.1 \cdot 10^{-3} \mathrm{~s}^{-1}$, respectively. The kinetic behaviour of the copolymers strongly depends on the type of nonchromophoric comonomer and is comparable for pairs of the copolymers containing the same comonomer. It was interesting that the rate constants of the fast process for copolymers containing butyl methacrylate as comonomer have the highest values $\left(57.16 \cdot 10^{-3} \mathrm{~s}^{-1}\right.$ for $\mathrm{p}(\mathrm{SMERm}-\mathrm{co}-\mathrm{MB})$ and $45.78 \cdot 10^{-3} \mathrm{~s}^{-1}$ for $\left.\mathrm{p}(\mathrm{SMERe}-\mathrm{co}-\mathrm{MB})\right)$, while the smallest values are observed for copolymers with isobornyl methacrylate. These results might be caused by limited free volume available in polymer chain, because the free volume around the chromophore plays an important role for the trans-cis photoisomerization process. Probably, the chromophore group in butyl methacrylate copolymers have greater freedom to move during isomerization cycle. In turn, the large size of the side groups of isobornyl methacrylate comonomer limits the movements of the azobenzene groups in polymer chain. The molecular movement of the chromophores and the mobility strongly depends on the free volume available around the chromophore molecule [34,55]. The photoisomerization rates exhibited comparable relationship between the two series of polymers described in this work. Surprisingly, the highest photoisomerization rates were observed for homopolymers, possessing the largest values $\mathrm{T}_{\mathrm{g}}$ of calculated elastic moduli and densities, as presented in Table 3. The intermediate values were observed for butyl methacrylate copolymers, and the lowest for isobornyl methacrylate copolymers. The photoismerization rates seems to depend on the average molecular weights of polymers (Table 1). The $\mathrm{M}_{\mathrm{w}}$ 's of the hompolymers (more 
precisely oligomers) were much lower than those determined for copolymers, what can affect the chromophore moieties mobility.

a)

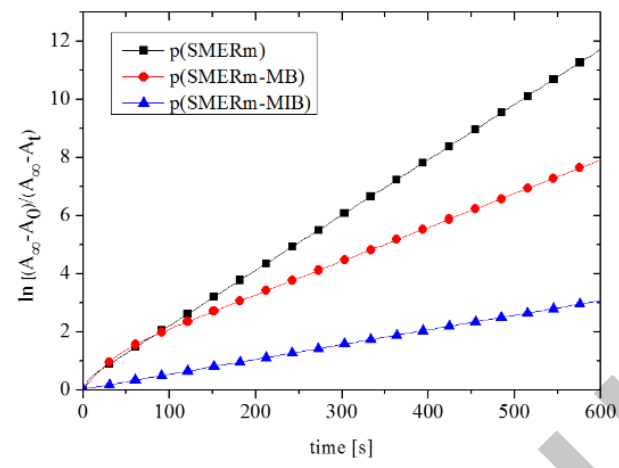

b)

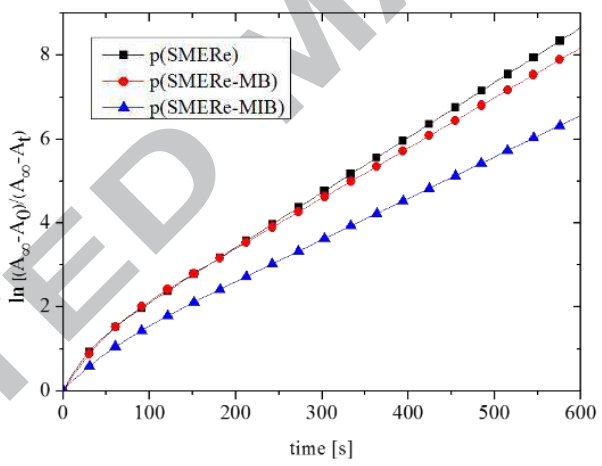

Figure 4. Kinetics of the trans-cis photoisomerization induced by illumination with laser: a) polymers containing SMERm azo-derivative b) polymers containing SMERe azo-derivative.

Subsequently, kinetic aspects of the cis-trans isomerization of the azo group in the obtained polymers were studied. The thermal relaxation process was analysed by the firstorder kinetics expression in equation (2):

$$
\left(A_{0}-A_{t}\right) /\left(A_{0}-A_{\infty}\right)=\alpha^{\prime} \cdot \exp \left(-k_{1}^{\prime} \cdot t\right)(2)
$$

where $\mathrm{k}_{1}$ is rate constant related to the cis-trans isomerization, $\alpha$ describes the fraction in total conversion of the system, $\mathrm{A}_{0}$ is an initial absorbance (before irradiation), $\mathrm{A}_{\infty}$ is absorbance in the photostationary state and $A_{t}$ represents absorbance measured at time $t$. All investigated 
polymers relaxed with a similar rate. Values of rate constants of the thermal relaxation are in the range of $1.6-2.6 \cdot 10^{-4} \mathrm{~s}^{-1}$.

In this experiment we observed that the trans-cis photoizomerization induced by light illumination is significantly faster process than the thermal relaxation at ambient temperature. These relationship can be explained with the fact that the thermal relaxation process occurs at ambient conditions without any external stimuli. The comparison of kinetics of the thermal relaxation is presented in Figure 5.

a)

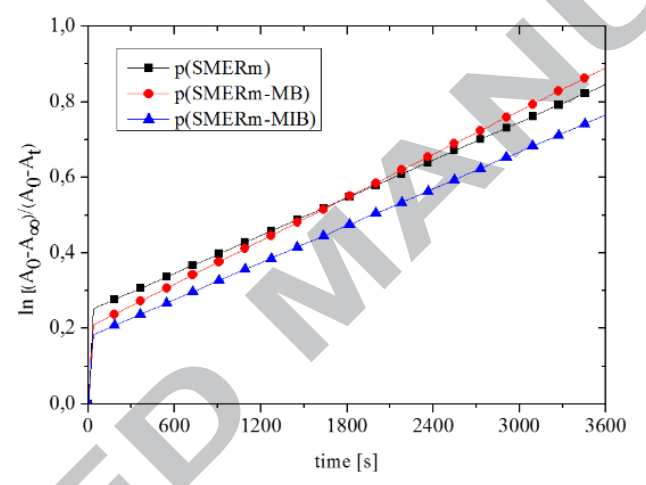

b)

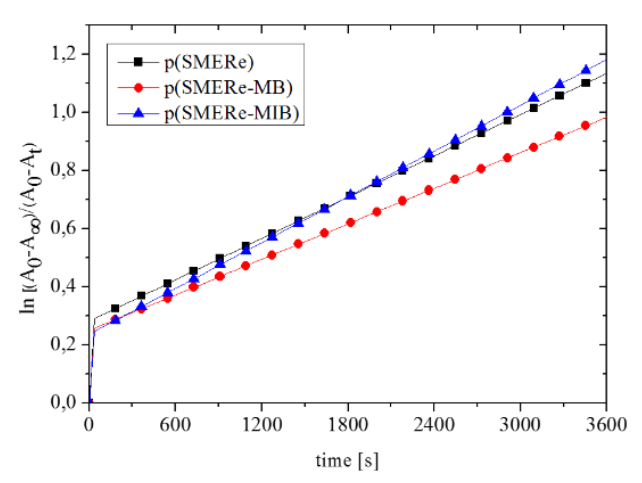

Figure 5. Kinetics of thermal relaxation in the dark: a) polymers containing SMERm azoderivative, b) polymers containing SMERe azo-derivative.

Afterwards, the ellipsometric investigations were carried out. Ellipsometry is an optical method for measurements of optical parameters of thin layers by evaluation of polarization state of reflected light. Ellipsometry technique enable to determine two parameters: $\Psi$ and $\Delta$. 
The $\Psi$ parameter indicates intensity ratio of reflected polarized light and the $\Delta$ parameter is defined as phase shift of polarized light. This method made it possible to observe changes of the both parameters during irradiation with laser. These changes are used to calculate refractive index changes of the samples (3):

$$
n=n_{r}+i k(3)
$$

where $n_{r}$ is defined as the real part of refractive index and ik represents imaginary part of refractive index, $\mathrm{k}$ is extinction coefficient.

The measurements were performed in a continuous way using the thin photochromic polymer films. All samples were illuminated for the same period of time, this is 3 minutes. After that, the samples were allowed to relax thermally for 6 minutes. The light source used in experiment was laser with wavelength $445 \mathrm{~nm}$ and power of $18 \mathrm{~mW}$. After sample illumination, significant changes of the both ellipsometric parameters and the real part of refractive index were observed for all materials. Depending on the polymer, the change of refractive index was in the range of 0.010-0.053. The changes of the real part of the complex refractive index are presented in Table 1. Similar changes of both ellipsometric parameters during illumination were observed for all investigated samples. Relationships between change of $\Psi$ and $\Delta$ parameters during irradiation are shown in Figure 6 and 7.

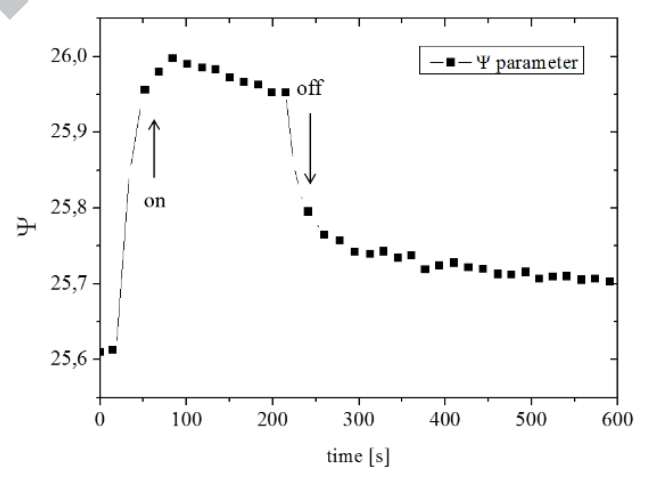

Figure 6. Change of the ellipsometric parameter $\Psi$ of the homopolymer $\mathrm{p}(\mathrm{SMERe})$ under irradiation with laser beam $(\lambda=445 \mathrm{~nm})$. 


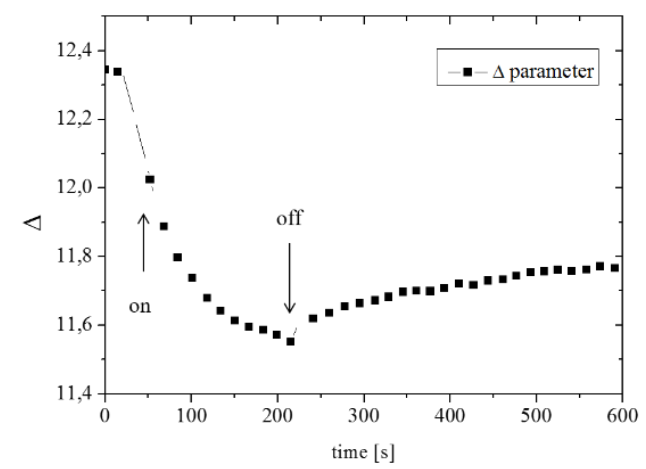

Figure 7. Change of the elliprometric parameter $\Delta$ of the homopolymer $\mathrm{p}(\mathrm{SMERe})$ under irradiation with laser beam $(\lambda=445 \mathrm{~nm})$.

The ellipsometric measurements enabled us to confirm the photochromic properties and ability to trans-cis photoisomerization of the azobenzene derivatives in the synthesized polymers.

\subsection{Surface Relief Grating formation}

The potential use of synthesized polymers as holographic recording materials was examined by surface relief grating formation. The experimental setup uses only one laser beam with controlled polarization in a one-step irradiation process to photoinduce a spontaneous SRG. A linearly polarized $\mathrm{Ar}^{+}$laser beam at $473 \mathrm{~nm}$ and $400 \mathrm{~mW} / \mathrm{cm}^{2}$ power was used as the light source. Each sample of the azopolymer thin film was illuminated for 1 hour. All of the samples were irradiated for the same time. The wavelength of laser beam used for a spontaneous SRG inscription was located in the range of the absorption band of the synthesized polymers. 


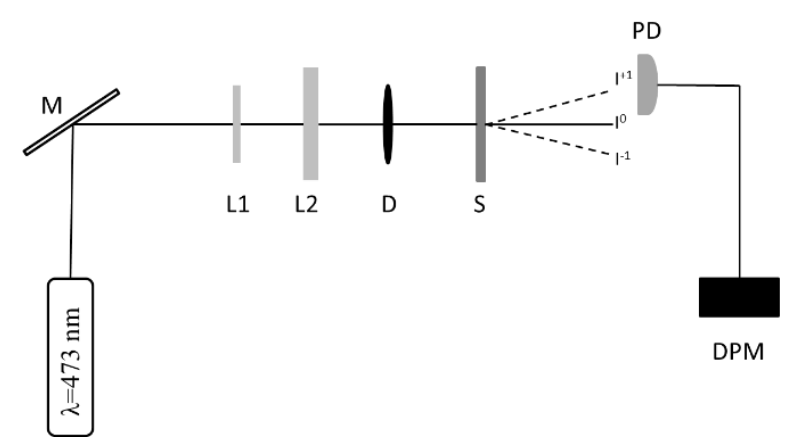

Figure 8. Scheme of the experimental set-up for recording surface relief grating with one beam method: M-mirror, L1, L2 - lenses, D - diaphragm, S - sample, PD - detector, DPM Digital Power Meter. Recording was conducted with laser $\lambda=473 \mathrm{~nm}$.

In all of the investigated polymer films, the surface relief grating was successfully inscribed. The surface profile of the grating of the homopolymer $\mathrm{p}(\mathrm{SMERe})$ is shown in Figure 9. The SRGs for the other azopolymers are quite similar to results presented in Figure 9. The parameters of the recorded spontaneous SRG were determined by AFM imaging and are given in Table 5.

a)

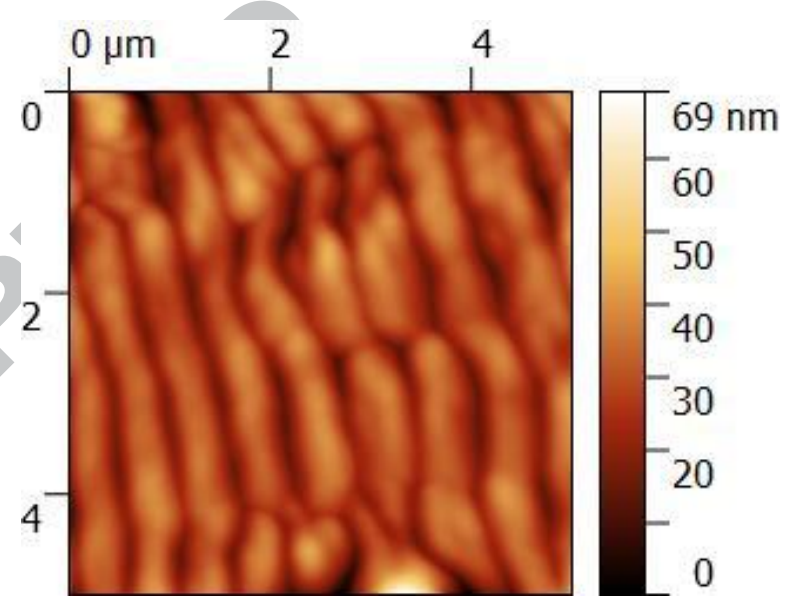

b)

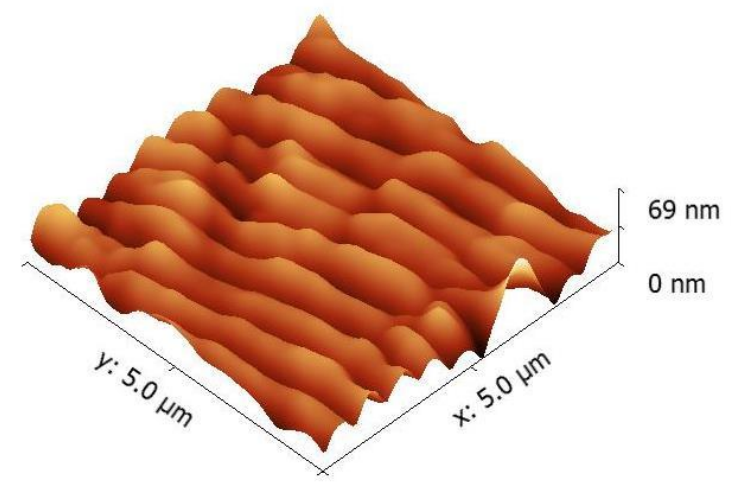


c)

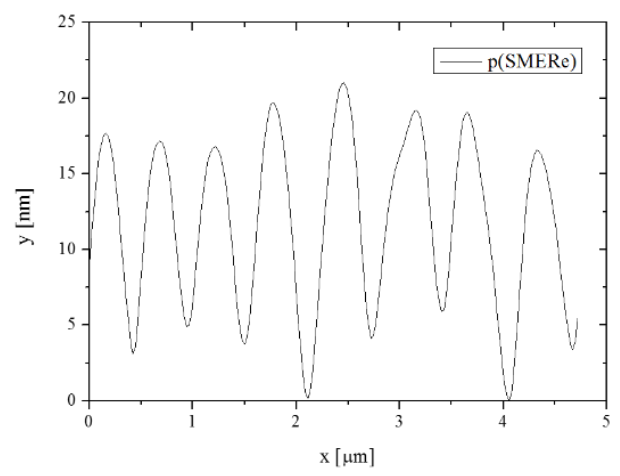

Figure 9. AFM images of homopolymer p(SMERe) film surface a) relief grating, b) threedimensional view of grating, c) relief grating profile.

We observed that the type of nonchromophoric comonomer plays an important role in the spontaneous SRG formation process. It is related to these physicochemical properties such as molecular weight and glass transition temperature. The characteristic polymer properties for a series of synthesized polymers with azo derivatives of sulfamerazine are summarized in Table 1.

The surface patterns inscribed on the thin films were imaged with an atomic force microscope. After 1 hour recording, we can observe a modulation with an average pitch (periodicity) $\Lambda=475-900 \mathrm{~nm}$, depending on the sample. The AFM measurements of the surface gratings show a depth (amplitude) of the modulation in the range of 15-85 $\mathrm{nm}$. The periodicity of patterns depends on the incident angle of the laser beam and can be modified by changing the angle. The period can be estimated following the empirical law:

$$
\Lambda=\frac{\lambda}{n_{r}(1-\sin (\theta))}
$$

where $\Lambda$ is the period of patterns, $n_{r}$ is the refractive index of the material, $\lambda$ is the wavelength and $\theta$ describes an incident angle [1,3,25].

According with the above equation, the refractive index influences the period of patterns. Hence, the differences of the periodicity between homopolymers and copolymers were observed. The calculated values of refractive index for homo- and copolymers as well as periods of spontaneous surface relief gratings inscribed on the surface of azopolymer thin films are found to be in good agreement with the empirical equation (4). According to that equation, the grating period is inversely proportional to the refractive index of the material in question. Therefore, for copolymers, in case of which we determined lower values od 
refractive index, we observed larger periods of spontaneous surface relief gratings. For homopolymers the results are opposite but still remain in accordance with the equation (4). The experimental conditions (incident angle, wavelength, polarization and intensity of the laser beam) were the same for all the samples.

Moreover, after illumination with laser, experimental diffraction efficiencies $\eta$ were determined according to the formula [56]:

$$
\eta=\left(I_{1} / I_{0}\right) \cdot 100 \%
$$

where $I_{1}$ is the intensity of the diffracted light in the first order diffraction and $I_{0}$ the intensity of the incident light.

As a general tendency, the diffraction efficiencies were higher for copolymers (6-14\%) than for homopolymers (2-4\%). In case of copolymer p(SMERm-co-MIB) the largest diffraction efficiency was observed $(\sim 14 \%)$. For copolymer p(SMERe-co-MB) it was only slightly less: $\sim 9 \%$.

In case of surface relief grating inscription we noticed the opposite relationship between the polymer surface modulation depth and the polymer type comparing to results related to photoisomerization kinetics. The polymers susceptibility to laser irradiation in terms of spontaneous SRG inscription efficiency seems to correlate with their properties estimated by computer simulations. The modulation depth was the lowest for homopolymers, which according to the calculated results are the stiffest materials among all other (they have distinctly higher values of density and Young modulus than the copolymers, refer to Table 3). Another interesting difference between homopolymers and copolymers is molar heat capacity, which in case of homopolymers was significantly higher than for copolymers. This property may also affect the material susceptibility to efficient spontaneous SRG formation. The highest modulation depths observed for copolymers containing isobornyl methacrylate can be explained by the advantageous influence of large nonchromophoric side groups, which efficiently separate the chromophore molecules and make them more accessible to laser radiation.

Table 5. Periodicity $(\Lambda)$ and amplitude $(A)$ of surface modulation and the diffraction efficiency $(\eta)$ for SRG inscription in the azopolymer thin films.

\begin{tabular}{|c|c|c|c|c|c|c|}
\hline Polymer & $\mathbf{p}$ (SMERm) & $\begin{array}{c}\mathbf{p} \text { (SMERm- } \\
\text { co-MB) }\end{array}$ & $\begin{array}{c}\mathbf{p} \text { (SMERm- } \\
\text { co-MIB) }\end{array}$ & $\mathbf{p}$ (SMERe) & $\begin{array}{c}\mathbf{p} \text { (SMERe- } \\
\text { co-MB) }\end{array}$ & $\begin{array}{c}\mathbf{p} \text { (SMERe- } \\
\text { co-MIB) }\end{array}$ \\
\hline A [nm] & 20 & $30-55$ & 85 & $15-25$ & 40 & 70 \\
\hline
\end{tabular}




\begin{tabular}{|l|l|l|l|l|l|l|}
\hline $\boldsymbol{\Lambda} \mathbf{~ n m ]}$ & 475 & 785 & 865 & 525 & 890 & 900 \\
\hline $\boldsymbol{\eta}[\mathbf{\%}]$ & 4.3 & 6.4 & 13.9 & 2.1 & 8.5 & 2.1 \\
\hline
\end{tabular}

\section{Conclusion}

In summary, a series of novel photochromic polymers containing azo derivatives of sulfamerazine have been successfully synthesized and characterized. All polymers were obtained with satisfactory yields excessing $85 \%$. Furthermore, their photoisomerization and holographic behaviour was reported. Obtained polymer materials containing chromophores were irradiated with laser with a wavelength within the absorption band, leads to a trans-cis isomerization of the dye molecules. All of the obtained polymers exhibited similar photoresponsive behaviour. The reversible trans-cis photoisomerization of all investigated polymers was monitored by UV-Vis spectroscopy. Moreover, based on UV-Vis measurements, the kinetic study was carried out. Photoisomerization of the azobenzene derivatives chromophores was reversible in all investigated materials. The observation of this phenomenon in ellipsometric measurements confirmed photochromic properties of the synthesized polymers. The determined change of refractive index during illumination with laser was in the range of 0.010-0.053. All of the measured azopolymer thin films exhibited an ability to form surface relief gratings upon irradiation with one laser beam with $473 \mathrm{~nm}$ wavelength. Spontaneous SRGs were formed on the polymer films by irradiating linearly polarized $\mathrm{Ar}^{+}$laser for 1 hour. Surface relief gratings have been inscribed on polymer films at identical recording conditions. In all cases spontaneous SRGs were formed successful and characterized by regular sinusoidal surface modulation. Depends on the polymer, the diffraction efficiency was in the range of $2.1-13.9 \%$. Based on these preliminary results, we suppose that this kind of the photoresponsive materials may find the potential applications in photonics for information recording by holographic procedures. However, further investigation will be carried out.

\section{Acknowledgements}

The research was supported by a statutory activity subsidy from the Polish Ministry of Science and Higher Education for the Faculty of Chemistry of Wrockaw University of Technology. 
Authors wish to thank to Sylvie Dabos from MOLTECH-Anjou Laboratory, Angers, France for AFM characterizations.

Calculations have been carried out using resources provided by Wroclaw Centre for Networking and Supercomputing (http://wcss.pl), grant No. 271

Materials Studio software was utilized within the Biovia Polish Country WideLicense.

\section{References}

[1] C. Hubert, C. Fiorini-Debuisschert, L. Rocha, P. Raimond, J.M. Nunzi, Spontaneous photoinduced patterning of azo-dye polymer films: the facts, J. Opt. Soc. Am. B 24 (8) (2007) 1839-1846.

[2] S.K. Na, J.S. Kim, S.H. Song, Ch. H Oh, Y.K. Han, Y.H Lee, S.G. Oh, Efficient formation of surface relief grating on azopolymer films by gold nanoparticles, J. Appl. Phys. 104 (2008) 103117.

[3] A. Natansohn, P. Rochon, Photoinduced motions in azocontaining polymers, Chem. Rev. 102 (2002) 4139- 4175.

[4] E. Ortyl, J. Jaworowska, P.T. Seifi, R. Barille, S. Kucharski, Photochromic polymer and hybrid materials containing azo methylisoxazole dye, Soft Mater. 9 (4) (2011) 335-346.

[5] M.J. Lee, D.H. Jung, Y.K Han, Photo-responsive polymers and their applications to optical memory, Mol. Cryst. Liq. Cryst. 444 (2006) 41-50.

[6] X. Y. Zhao, M. Z. Wang, Structure dependence of photochromism and thermochromism of azobenzene-functionalized polythiophenes, Express Polym. Lett. 1 (7) (2007) 450-455.

[7] I. Moleavin, S. Grama, I. Carlescu, D. Scutaru, N. Hurduc, Photosensitive micelles based on polysiloxanes containing azobenzene moieties, Polym. Bull. 65 (2010) 6981.

[8] Y. Wu, A. Natansohn, P. Rochon, Photoinduced birefringence and surface relief gratings in polyurethane elastomers with azobenzene chromophore in the hard segment, Macromolecules 37 (2004) 6090-6095.

[9] Y. Zhao, T. Ikeda, Smart Light-Responsive Materials: Azobenzene-containing polymers and Liquid Crystals, John Wiley\&Sons, New Jersey 2009. 
[10] I. Sava, S.M. Resmerita, G. Lisa, V. Damian, N. Hurduc, Synthesis and photochromic behavior of new polyimides containing azobenzene side groups, Polymer 49 (2008) 1475-1482.

[11] L. Ding, T.P. Russel, A photoactive polymer with azobenzene chromophore in the side chains, Macromolecules 40 (2007) 2267-2270.

[12] T. Fukuda, H. Matsuda, T. Shiraga, T. Kimura, M. Kato, N.K. Viswanathan, J. Kumar, S.K. Tripathy, Photofabrication of surface relief grating on films of azobenzene polymer with different dye functionalization, Macromolecules 33 (2000) 4220-4225.

[13] A. Sobolewska, S. Bartkiewicz, A. Priimag, High-modulation-depth surface relief gratings using $\mathrm{s}^{-} \mathrm{s}$ polarization configuration in supramolecular polymer-azobenzene complexes, J. Phys. Chem. C 118 (2014) 23279-23284.

[14] A. Klaikherd, C. Nagamani, S. Thayumanavan, Multi-stimuli sensitive amphiphilic block copolymer assemblies, J. Am. Chem. Soc. 131 (2009) 4830-4838.

[15] R. Castagna, F. Vita, D.E. Lucchetta, L. Criante, F. Simoni, Superior-performance polymeric composite materials for high-density optical data storage, Adv. Mater 21 (2009) 589-592.

[16] A.R. Luca, L. Rocha, A.M. Resmerita, A. Macovei, M. Hamel, A.M. Macsim, N. Nichita, N. Hurduc, Rigid and flexible azopolymers modified with donor/acceptor groups. Synthesis and photochromic behavior, Express Polym. Lett. 5 (11) (2011) 959969.

[17] E. Ortyl, R. Janik, S. Kucharski, Methylacrylate polymers with photochromic side chains containing heterocyclic sulfonamide substituted azobenzene, Eur. Polym. J. 38 (2002) 1871-1879.

[18] Q. Tang, X. Meng, H. Jiang, T. Zhou, C. Gong, X. Fu, S. Shi, Synthesis and characterization of photo- and $\mathrm{pH}$-responsive nanoparticles containing aminosubstituted azobenzene, Journal of Materials Chemistry 20 (2010) 9133-9139.

[19] H. M. D. Bandarab, S.C. Burdette, Photoisomerization in different classes of azobenzene, Chem. Soc. Rev. 41 (2012) 1809-1825.

[20] V. Borger, S. Pohle, O. Kuliskovska, K. Gharaggozloo-Hubmann, J. Stumpe, H. Menzel, Azobenzene-containing polymers for surface relief grating, Macromolecular Symposia 275-276 (2009) 257-265.

[21] J. Aleksejeva, J. Teteris, U. Gertners, Photoinduced mass transport in soft materials, Materials Science and Engineering 23 (2011) 012002. 
[22] E. Potanina, J. Teteris, Photo-induced formation of surface relief in amorphous $\mathrm{As}_{2} \mathrm{~S}_{3}$ films, Chalcogenide Lett. 10 (11) (2013) 449-454.

[23] D.G. Perez, R. Barille, Y. Morille, S. Zielińska, S. Ortyl, Multifractal characteristics of optical turbulence measured through a single beam holographic process, Opt. Express 22 (16) (2014) 19538-19545.

[24] A. Ambrosio, S. Girardo, A. Camposeo, D. Pisignano, P. Maddalena, Controlling spontaneous surface structuring of azobenzene-containing polymers for large-scale nano-lithography of functional substrates, Appl. Phys. Lett. 102 (2013) 093102.

[25] R. Barille, R. Janik, S. Kucharski, J. Eyer, F. Letournel, Photo-responsive polymer with erasable and reconfigurable micro- and nano-patterns: An in vitro study for neuron guidance, Colloids Surface B. 88 (2011) 63-71.

[26] S. Ahmadi-Kandjani, R. Barille, S. Dabos-Seignon, J.M. Nunzi, E. Ortyl, S. Kucharski, Multistate polarization addressing using a single beam in an azo polymer film: Opt. Lett., 30 (15) (2005) 1986-1988.

[27] L. Mazaheri, S. Ahmadi-Kandjani, J.M. Nunzi, Influence of temperature on the relaxation kinetics of spontaneous pattern formation in an azo-polymer film: Opt. Commun. 298-299 (2013) 150-153.

[28] L. Mazaheri, S.R. Bobbara, O. Lebel, J.M. Nunzi, Photoinduction of spontaneous surface relief gratings on Azo DR1 glass: Opt. Lett. 41 (13) (2016) 2958-2961.

[29] D.Y. Kim, S.K. Tripathy, L. Li, J. Kumar, Laser-induced holographic surface relief gratings on nonlinear optical polymer films, Appl. Phys. Lett. 66 (10) (1995) 11661168.

[30] P. Rochon, E. Batalla, A. Natansohn, Optically induced surface relief gratings on azoaromatic polymer films, Appl. Phys. Lett. 66 (2) (1995) 136-138.

[31] O.N. Oliveira Jr, D.S. dos Santos Jr, D.T. Balogh, V. Zucolotto, C.R. Mendonca, Optical storage and surface-relief gratings in azobenzene- containing nanostructured films, Adv. Colloid Interfac. 116 (2005) 179-192.

[32] L.L. Carvalho, T.F.C. Borges, M.R. Cardoso, C.R. Mendonça, D.T. Balogh, Molecular weight effect on the photoinduced birefringence and surface relief gratings formation of a methacrylate azopolymer, Eur. Polym. J. 42 (2006) 2589-2595.

[33] O.N. Oliveira Jr, J. Kumar, L. Li, S.K. Tripathy, Surface-Relief Gratings on Azobenzene-Containing Films, in: Z. Sekkat, W. Knoll (Eds.), Photoreactive Organic Thin Films, Elsevier Science, USA, 2002, vol 1, pp. 429-486. 
[34] V. Börger, H. Menzel, M.R. Huber, Influence of the molecular weight of azopolymers on the photo-induced formation of surface relief gratings, Mol. Cryst. Liq. Cryst. 430 (2005) 89-97.

[35] H. Z. Cao, W. Zhang, J. Zhu, X. R. Chen, Z. P. Cheng, J. H. Wu, X. L. Zhu, Azo polymers with electronical push and pull structures prepared via RAFT polymerization and its photoinduced birefringence behavior, Express Polym. Lett. 2(8) (2008) 589601 .

[36] J. Noga, A. Sobolewska, S. Bartkiewicz, M. Virkki, A. Priimagi, Periodic Surface Structures Induced by a Single Laser Beam Irradiation, Macromol. Mater. Eng. 2016, doi:10.1002/mame.201600329

[37] L. Mazaheri, R.G. Sabat, O. Lebel, J.-M. Nunzi, Unraveling the nucleation and growth of spontaneous surface relief gratings, Opt. Mater. 62 (2016) 378-391.

[38] L. Mazaheri, S. Ahmadi-Kandjani, J.-M. Nunzi, Influence of temperature on the relaxation kinetics of spontaneous pattern formation in an azo-polymer film, Opt. Commun. 298-299 (2013) 150-153. [39] M. Serwadczak, M. Wübbenhorst, S. Kucharski, Optical and broadband dielectric investigations of photochromic polymethacrylates, J. Non-Cryst. Solids 353 (2007) 4303-4312.

[40] E. Ortyl, S. Kucharski, Kinetics of refractive index changes in polymeric photochromic films, Macromolecular Symposium 212 (2004) 321-326.

[41] S. Zielińska, E. Ortyl, R. Barille, S. Kucharski, Preparation and characteristics of new chiral photochromic copolymers, Opt. Mater. 32 (2009) 198-206.

[42] E. Ortyl, S. Kucharski, T. Gotszalk, Refractive index modulation in the polyurethane films containing diazo sulfonamide chromophores, Thin solid films 479 (2005) 288296.

[43] S. Kucharski, R Janik., P. Kaatz, First hyperpolarizability of the heterocyclic sulfonamides for Langmuir-Blodgett films by calculation, solvatochromism and Hyper-Rayleigh scattering, J. Phys. Chem. B 101 (44) (1997) 8967-8974.

[44] A. Bućko, S. Zielińska, E. Ortyl, M. Larkowska, R. Barille, Synthesis of organicinorganic hybrid azobenzene materials for the preparation of nanofibers by electrospinning, Opt. Mater. 38 (2014) 179-187.

[45] M. Serwadczak, M. Wübbenhorst, S. Kucharski, Optical and dielectric characteristics of photochromic hybrid sol-gel materials, J. Sol-Gel Sci. Technol. 40 (2006) 39-44. 
[46] J. Raźna, P. Hodge, D. West, S. Kucharski, NLO properties of polymeric LangmuirBlodgett films of sulfonamide-substituted azobenzenes, J. Mater. Chem. 9 (1999) 1693-1698.

[47] R. Barille, P. Tajalli, S. Zielińska, E. Ortyl, S. Kucharski, J.M. Nunzi, Surface relief grating formation on nano-objects, Appl. Phys. Lett. 95 (2009) 053102.

[48] Gaussian 09, Revision E.01, M. J. Frisch, G. W. Trucks, H. B. Schlegel, G. E. Scuseria, M. A. Robb, J. R. Cheeseman, G. Scalmani, V. Barone, B. Mennucci, G. A. Petersson, H. Nakatsuji, M. Caricato, X. Li, H. P. Hratchian, A. F. Izmaylov, J. Bloino, G. Zheng, J. L. Sonnenberg, M. Hada, M. Ehara, K. Toyota, R. Fukuda, J. Hasegawa, M. Ishida, T. Nakajima, Y. Honda, O. Kitao, H. Nakai, T. Vreven, J.A. Jr. Montgomery, J.E. Peralta, F. Ogliaro, M. Bearpark, J.J Heyd, E. Brothers, K.N. Kudin, V.N. Staroverov, R. Kobayashi, J. Normand, K. Raghavachari, A. Rendell, J.C. Burant, S.S. Iyengar, J. Tomasi, M. Cossi, N. Rega, J.M. Millam, M. Klene, J.E. Knox, J.B. Cross, V. Bakken, C. Adamo, J. Jaramillo, R. Gomperts, R.E. Stratmann, O. Yazyev, A.J. Austin, R. Cammi, C. Pomelli, J.W. Ochterski, R.L. Martin, K. Morokuma, V.G. Zakrzewski, G.A. Voth, P. Salvador, J.J. Dannenberg, S. Dapprich, A.D. Daniels, Ö. Farkas, J.B. Foresman, J.V. Ortiz, J. Cioslowski, D.J. Fox, Gaussian, Inc., Wallingford CT, 2009.

[49] S. Zielińska, M. Larkowska, S. Kucharski, New multifunctional sulfonamidecontaining azobenzene chromophores: Synthesis and photochromic properties, Dyes Pigments 92 (2012) 1018-1024.

[50] H.J. Haitejma, R. Buruma, G.O. Alberda, Y.Y. Van, G. Ekenstein, New photoresponsive (methyl)acrylate (co)polymers containing azobenzene pendant sidegroups with carboxylic and dimethyloamino substituents: I. Synthesis and characterization of the monomers, Eur. Polym. J. 32 (12) (1996).

[51] S. Xie, A. Natansohn, P. Rochon, Microstructure of copolymers containing disperse red 1 and methyl methacrylate, Macromolecules 27 (1994) 1885-1890.

[52] X. Jiang, X. Chen, X. Yue, J. Zhang, S. Guan, H. Zhang, W. Zhang, Q. Chen, Synthesis and characterization of photoactive poly(arylene ether sulfone)s containing azobenzene moieties in their main chains, Reactive \& Functional Polymers 70 (2010) $616-621$.

[53] R. Barille, P. Tajalli, S. Kucharski, E. Ortyl, J.M. Nunzi, Photoinduced deformation of azopolymer nanometric spheres, App. Phys. Lett. 96 (2010), 163104-1-163104-3. 
[54] C. Barrett, B. Choughury, A. Natansohn, P. Rochon, Azocarbazole polymethacrylates as single-component electrooptic materials, Macromolecules 31 (1998) 4845-4851.

[55] S.K. Yesodha, C.K. Sadashiva Pillai, N. Tsutsumi, Stable polymeric materials for nonlinear optics: a review based on azobenzene systems, Prog. Polym. Sci. 29 (2004) 45-74.

[56] H. Taunaumanga, M. Solygac, M.O. Tijaa, A. Miniewicz, On the efficient mixed amplitude and phase grating recording in vacuum deposited Disperse Red 1, Thin Solid Films 461 (2004) 316-324.

1. A series of highly photoactive polymers containing azo derivatives of sulfamerazine was described.

2. Photoisomerization behavior has been extensively studied in thin azopolymer films.

3. The synthesized polymers show an ability to self-organize into regular, periodical surface relief structures during illumination with single laser beam.

4. The new computational approach to explain the polymers behavior under illumination was also proposed.

Graphical abstract

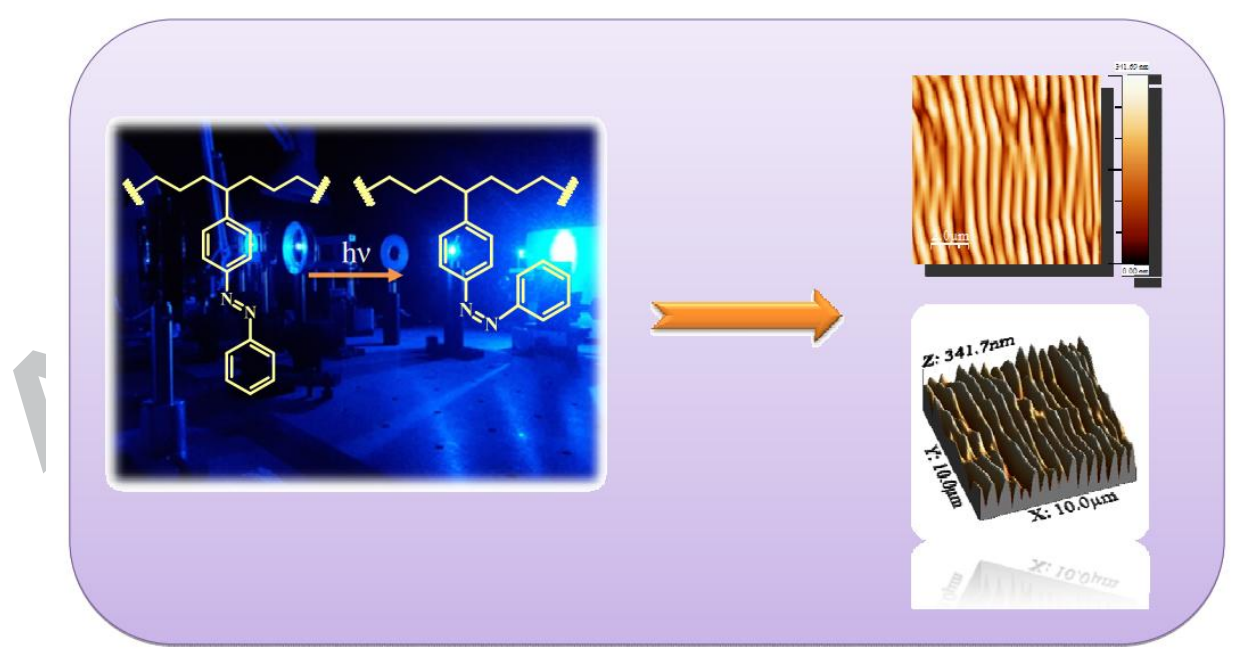

